THESIS

378.7

M71

XY85

UM Libraries Depository

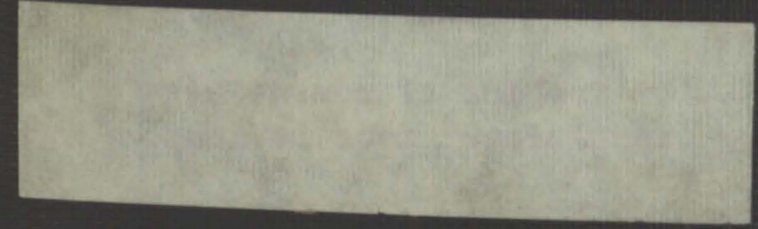




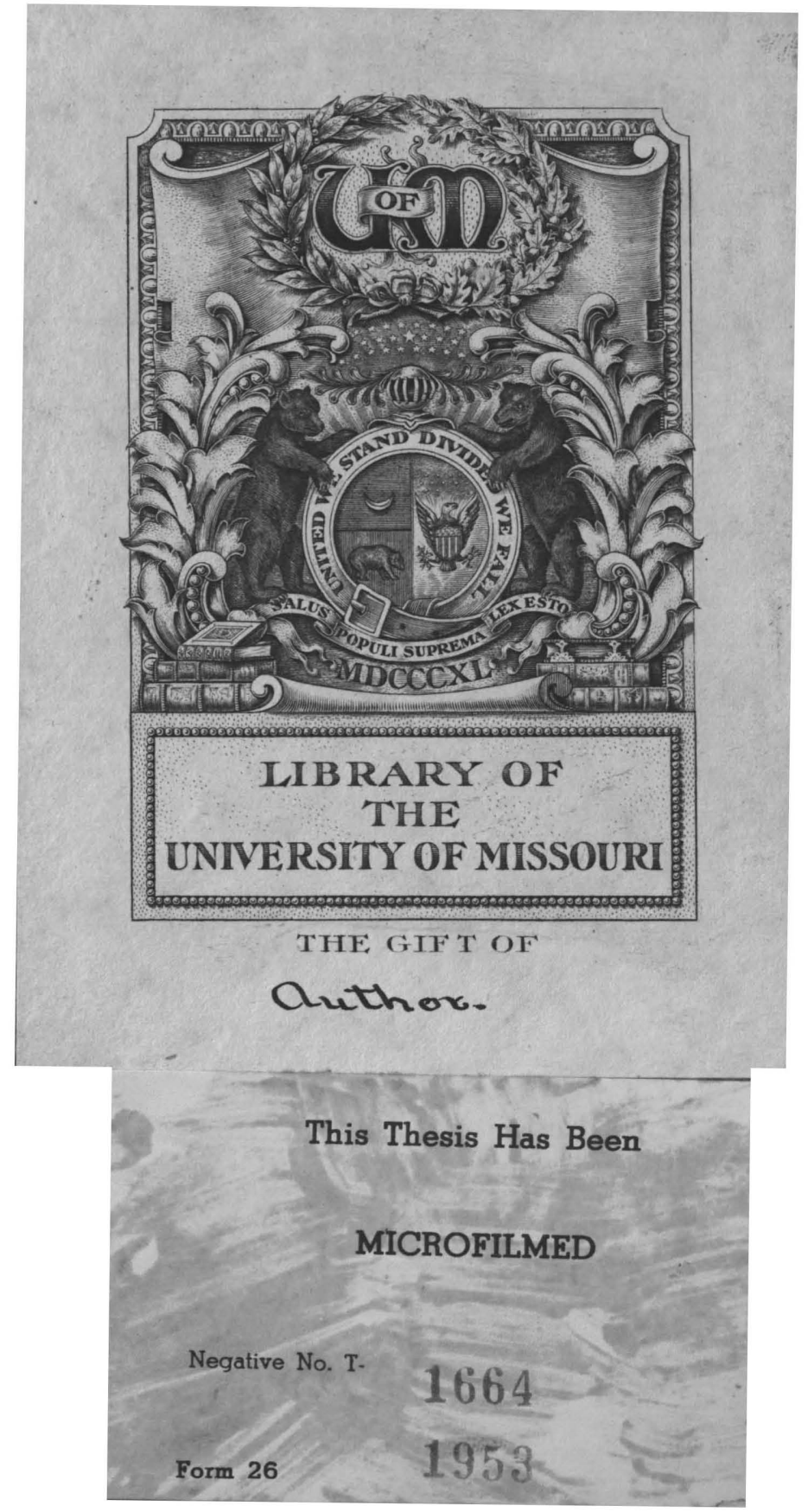








\section{RELATION OF THE GLOCHIDIUM OF FRESH-WATER MUSSELS TO THE TISSUES OF THE HOST}

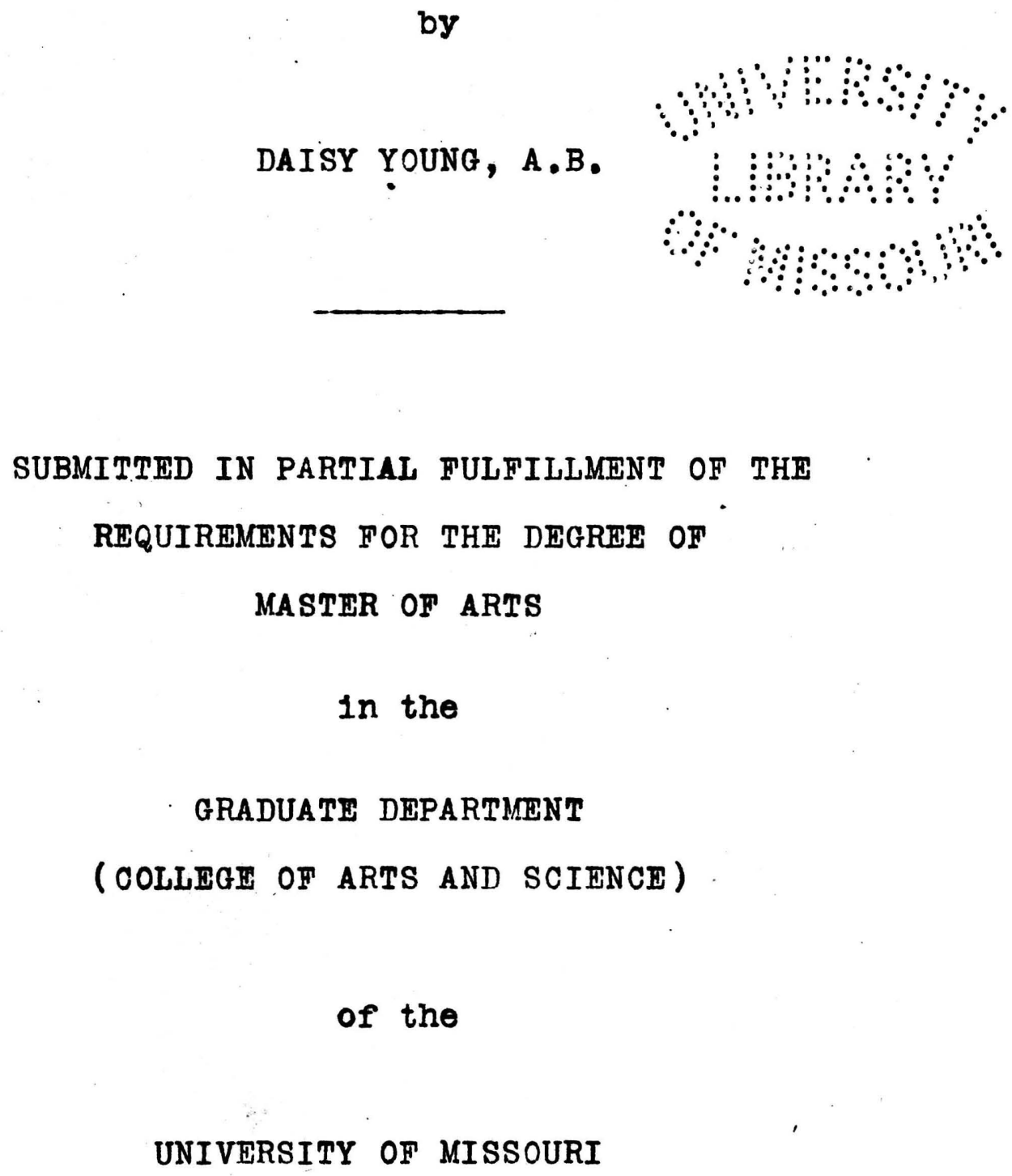



RELATION OF THE GLOCHIDIUM OF FRESH-WATER MUSSELS

TO THE TISSUES OF THE HOST.

The present study, which has been made in connection with the investigations now being carried on at the University of Missouri for the U. S. Bureau of Fisheries on the artificial propagation of fresh water mussels, was undertaken in order to determine the precise changes that take place in the tissues of fishes as a result of the parasitism of the glochidia.

\section{Reproduction and Life-history of the Unionidae.}

As is well known, the Unionidae carry their young in the gills, which act as a marsupium or brood-chamber, until the completion of the embryonic development. The eggs are passed from the ovaries into the suprabranchial chambers, where they are fertilized by spermatozoa brought in by the inhalent current of water. In many species, the eggs are boun together in masses by a gelatinous or glutinous matrix which is secreted by the gills and which may be very tenacious. Th1s, however, in most cases gradually dissolves away as development proceeds, until at the close of the embryonic period the larvae or glochidia are no longer agglutinated. These masses assume many different forms of flat plates or cylindrical cords which fill the water tubes. The latter may be greatly distended or modified in various ways to receive the egg-masses. In some species, on the other hand, the condition 

Just described is absent and the eggs are elther not agglutinated at all or are only loosely held together in a slightly viscid substance.'

The extent to which the gills are modified as a marsupium varies greatly in different genera. In many, as in Anodonta, Symphynota, and Unio, the entire outer gill of each side is thus utilized and when filled with embryos or glochidia, presents a much swollen pad-like appearance. In others, for example, Lampsilis, Obovaria, Plagiola, only the posterior portion, varying from one to two thirds of the entire outer gill, is used as a receptacle for the eggs, a sharp demarcation existing between the marsupial region and the anterior respiratory part. The former is highly modified in structure and may be readily recognized, even when empty. Finally there are at least two genera, namely, Quadrula and Fritigonia, in which all four gills are utilized as broodchambers. This condition would seem to be the most primitive one, as the gills show but little structural modification and when empty are indistinguishable from those of the male.

The entire embryonic development takes place within the marsupium, and at the end of this period the glochidium, which has become liberated from the egg-membrane within the gill, is fully formed. In those species which are known as "Bummer-breeders", the glochidia are discharged at once, while in many others, the so-called "winter-breeders", they are carried in the gills for many months before being set free in the water. 

The glochidia, as has long been known, do not complete their development unless they become attached to fish, and, while living parasitically in a cyst formed by the epidermis of the host, the metamorphosis occurs. After discharge from the marsupium, the glochidia under natural conditions lie quiescent. on the bottom, their valves gaping widely apart, and unless chance brings them in contact with a.fish they will die without undergoing further change. Once attached to the gills or external parts of a fish, however, the rest of the development, if conditions are favorable, is assured. After a parasitic life of variable duration, during which the metamorphosis is completed, the cyst breaks down, and the young mussel, thus liberated, falls to the bottom, and leads thereafter an independent ife.

Two well marked types of glochidia occur in the Unionidae, one provided with stout hooks on the ventral margin of the valves, and the other entirely hookless. The former are characteristically parasitic on the fins and other external parts of the fish, the latter on the gills.

The hookless glochidia are usually much smaller than those which have hooks and also differ characteristically from the latter in shape.

The hooked glochidia form permanent attachment as a rule only to external parts of the fish, as the margins of the fins, operculum and mouth, the barbules, or even to scales and along the fin-rays ocoasionally. Wherever a free border 

1s presented that may be grasped between the valves of the glochidium, attachment is possible, the hooks holding securely as soon as the valves have closed. Hooked glochldia, furthermore, are not infrequently found on the gill arches and rakers, as these places furnish the requisite conditions for a firm grasp. Glochidia of this type, however, do not as a rule acquire a permanent lodgment on the delicate glll-filaments, as their hooks usually tear through them, when they are grasped. Their greater size would also seem to render it difficult for them to become properly embedded under the epidermis of the slender filament.

Hookless glochldia, on the other hand, are only rarely found on the external parts of the fish, and although they may become attached readily to such places, in the absence of hooks their grasp is insecure and the usual consequence is that they are all soon brushed off. Being hookless and quite small, they are admirably adapted to implantation on the gill-filaments, among which they may become entangled in great numbers. 

Materials and Methods.

The glochidia of Lampsilis ligamentinus and of Symphynota complanata were used as materials for the study of the relation of the parasite to the tissues of the host. The former, which are of the hookless type are essentially gill-parasites, while the latter are provided with hooks and usually acquire permanent attachment only to external parts of the fish.

Both species of mussels used belong to the group of so-called "winter-breeders", and, after carrying their glochidia in the gills throughout the fall and winter, normally discharge them during the following spring and early summer. A plentiful supply of glochidia is therefore easily obtained during the gravid period of the mussels, and infections have been made with them at frequent intervals.

The most successful infections were made on the green and red-spotted sun-fishes, Apomotis cyanellus, and Lepomis humilis, and on large-mouthed black bass, Micropterus salmo1-des. The crapple, Pomoxis annularis, was also used, but it is not so well sulted for infection, because it is difficult to keep these fishes alive in the laboratory until the completion of the parasitic period.

The glochidia were carefully removed from the gills of the mussels and placed with the fishes to be infected in small aquaria or other vessels. A comparatively small number of glochidia were used in order to guard against the danger 

have some influence, for the same difference in the period has been observed in the laboratory, where the temperature of the water remains practically constant throughout the winter and spring.

The following cases will illustrate this difference In the duration of the parasitic period. Black bass were infected with Lampsilis ligamentimus on Nov. 28, 1908, and after one hundred and fifteen days, that is on March 22, 1909, a few glochidia could still be found attached to the gills. Another infection was made on March 7th, again using the glochidia from Lampsilis ligamentimus. On April 7th the young mussels began to leave the fish, and within four days all had falien off. Here the period was thirty-four days. A third infection was made on April 8th, and in this case the glochldia remained on the fish only nineteen days.

In the case of the spring infections, the young clams all leave the fish at about the same time, and within a very few days after the first are liberated the last to go have come off. This is not true, however, of the fall and winter infections, for in these cases the setting free of the young mussels may be extended over a period of two or three weeks, or possibly more. 

Implantation of the Glochidia.

Sections of glochidia attached to the gills and fins, cut $5 \mu$ thick, and whole mounts of glochidia on gill filaments were studied. Both were stained with alumcochineal and the sections were counter-stained with eosin. The glochidium attaches itself to the fin or gill filament by closing its shell firmly over the epidermis. At once upon attachment to the fish, the epidermis of the latter in the immediate neighborhood of the glochidium begins a rapid proliferation. As has been states by Harms (5) and other observers, this proliferation of the epidemal cells is probably caused by the irritation produced by the wound, and is merely a healing process. At all events the glochidium exerts a stimulus upon the cells of the epidermis Which are thrown in consequence into active mitotic division. The newly-formed cells push up over the surface of the glochidial shell, and after a time form a complete cover. The cells divide mitotically and in no case has any evidence of amitotic division been observed.

The study of the changes which occur in the tissue of both the fins and gills of the fish was made exclusively on material obtained from winter infections, at which season, as has already been stated, the glochidia remain on the fish for from three to four months. The times mentioned in the following descriptions, therefore, refer solely to the long period of parasitism. 



\section{(a) Fin Infeotions.}

Figs. 1 and 2 show cross-sections of glochidia which have been attached to the fin one hour. The epidermal cells around the glochidium have begun to proliferate and in Fig.l cells may be seen in the process of mitotio division. Sometimes the glochidium in attaching itself to the epidermis injures the cells around it by mechanical pressure. They gradually become detached from the other cells and degenerate. The protoplasm appears hyaline and vacuolated and the nuclei contracted (Fig.1). Later these cells are sloughed off. The blood supply of the tissue forming the cyst is abundant. In both cross-sections referred to above many capillaries appear. In the intercellular spaces are numerous leucocyter. They are easily distinguished from the epidermal nuclel because they are much smaller and darker. Before the cyst is fully formed red blood corpuscles and leucocytes are often formed along the side of the glochidium. In many cases the red blood cells are degenerating and the nuclel are no longer small and dense, as they ordinarliy appear, but are much larger and clearer ( $F 1 g .1)$.

The shell hooks usually become turned in and pressed closely against the enclosed tissue, ( $f 1 g .3$ ) in this way making the grasp of the glochidium more secure. Sometimes, however, they become bent outward along the surface of the fin (Fig.4).

In the process of forming the epldermal covering around the parasite the cells divide most actively near the lower part of the glochidium. A mitosis may be seen in this 

position in the flsh tissue on each side of the glochidium show in Fig. 4. Dividing cells are rarely ever found in the upper part of the cyst at any time during 1ts formation. As the lower cells increase in number they push the ones above them up over the surface of the glochidium.

As Farssek (2) has described, the fish tissue which 1s enclosed within the mantle cavity of the glochidium disIntegrates and 18 taken up by the ectodermal cells of the larval mantle and used as food during the early stages of the parasitic life. Fig. 6 shows a cross-section through a glochidium in which the mantle cells are sending out pseudopodium-like processes, and within these cells are numerous leucocytes and fragments of the fish's cells sometimes enclosed In large vacuoles. Later as the edges of the permanent mantle are formed along the borders of the shell, the large cells of the embryonic mantle become pressed together more closely and pushed further into the mantle cavity, forming the "funguslike bodies" first described by Braun (1).

The time required for the glochidium to become entirely covered on the fin varies from six to twenty-four hours. Figs. 4 and 5 both show cross-sections of glochldia which have been attached to the same fin for six hours. In Fig. 4 the epidermis covers only about half of the glochidium, while in Fig. 5 it has grown over the entire glochidium completely embedding it. The changes which take place in the fin tissue after the complete inplantation of the parasite 

were not studied.

(b). Gill Infections.

The proliferation of the epidermis of the gill around an attached glochidium is much more rapid than that of the fin. This is very evident from a comparison of Figs. 1 and 6 . Fig. 6 shows a cross-section through a glochidium which has been attached to a gill filament for fifteen minutes. The growth of the epidermal tissue is more advanced than that of the fin, shown in Fig. I at the end of one hour. Schierholz (8) states that the time required for the formation of the cyst depends upon the size of the blood-vessels torn by the glochidium in the process of establishing itself upon the host. The blood-vessels of the gills are much larger than those of the fins and this probably accounts for the more rapid growth of the epidermis of the gill. Glochidia often become attached to two filaments lying close together and when this occurs the epidermis of both filaments grows up around the parasite to form the cyst. Figs. 15-18 are drawings of whole mounts of glochidia attached to gill-filaments and show the manner in which the epidermis pushes up over the glochidium to form the cyst.

The red blood cells and leucocytes found on the uncovered surface of the glochidium before the cyst is fully formed are more numerous in gill than in fin infections (Fig.6). This is due to the greater vascularity of the gills. Occasionally a large nucleus is found with these blood-cells (Fig.7). 'It is evidently a nucleus of one of the detached 

epidermal cells which has been carried out by the blood. Often large blood-vessels become enclosed with the tissue of the gills in the mantle cavity. (Fig.6). The cells of this tissue continue to divide for at least two hours after the attachment of the glochidium. Up to this time mitoses may often be seen. (Fig. 7 ).

Many leucocytes are usually found in the gill tissue just below the point where the glochidium is attached. (Figs. 6 and 7 ). This is due to an extensive hemorrhage caused by the tearing of the blood-vessels in tinis region, when the glochidium attaches itself to the gill.

The fish cells dividing to form the cyst must complete the entire process of division very quickly, since even in the rapidly growing gill tissue it is unusual to find more than two mitotic figures in one section. The glochidia on the gills usually become completely embedded in two hours after attachment, although it may require as much as six hours before they are entirely covered. Fig. 9 shows a crosssection of a glochidium of symphynota complanata, winich, contrary to the usual rule, has become implanted on the gill. Two hours after attachment the epidermis has entirely surrounded it. The cyst is at first very loose, and the cells are separated by large intercellular spaces. The bloodsupply is even more abundant than that of the cyst formed on the fin.

The epidermal cells continue to divide for two or three days. Mitoses are most often found just below the 

glochidium. (Fig, 10). Schierholz (8) states that the cyst continues to grow thicker until the third or fourth day, but in the specimen observed it apparently reached its maximum thickness at once. As the cells divide they become closely pressed together, and the tissue grows very compact, while the nuclei flattened against the shell of the parasite become elongated and oval in outline. (Fig. 10).

After the glochidium has remained on the fish about ten days, the tissue forming the cyst grows less dense. The intercellular spaces become enlarged and many of them contain red blood cells and leucocytes. As the lymph accumulates these spaces increase in size and the epidermal cells appear greatly elongated and connected by long protoplasmic processes. The nuclei are contracted and misshapen. After the tissue has assumed this appearance no further changes occur until the glochidium is ready to leave the fish. Fig. 12 shows a frontal section through a glochidium one hundred and one days after its attachment to the gills. It has at this time almost completed its metamorphosis and the tissue of the cyst presents the appearance described above. The cyst becomes looser because of these numerous lymph-spaces. During the last few days of the parasitic life slight movements of the foot may be observed in the glochidium, and it is probably through these movements that the cyst is burst open. Fig. 13 shows a young mussel in the process of freeing itself from the cyst. It is still attached to the end of a gill-filament but the cyst on one side has disappeared 

and on the other the cells are degenerating. When the young mussel leaves the flsh it usually carries with it fragments of the cyst, and these shreds of epidermis often cling to it for several days. 



\section{Explanation of Figures.}

All the figures are from camera lucida drawings. The drawings of sections were made with a $1 / 12$ inch oilimmersion objective, and those of whole mounts with a $3 / 4$ inch objective.

Figs. 1-5 represent sections of glochidia of symphynota complanata attached to fins of fishes. Figs. 6-8 and 10-13 represent sections of glochidia of Lampsilis ligamentinus attached to gills of fishes. Figs. 15-18 represent whole mounts of glochidia of Lampsilis ligamentinus attached to gill filaments.

Fig. 1. Cross-section of glochidium, one hour after attachment, showing mitoses, injured fish epidermal cells around glochidium in the process of degenerating, and blood cells on the uncovered surface of the glochidium.

Fig. 2. Cross-section of glochidium one hour after attachment showing the tissue in the immediate neighborhood of the glochidium presenting a more normal appearance than that shown in Fig.l. 



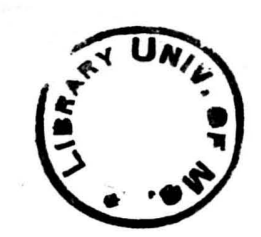

Fig. 3. Cross-section of glochidium three hours after attachment, showing the appearance of the fin tissue at this time and the position in which the shell hooks are usually found.

Fig. 4. Cross-section of glochidium six hours after attachment showing the cells of the larval mantle taking up the fish's cells enclosed between valves of glochidium, shell hooks bent outward, and a mitoses in the fish tissue on each side of glochidium.

Fig. 5. Cross-section of glochidium six hours after attachment, showing the glochidium completely embedded.

Fig. 6. Cross-section of glochidium fifteen minutes after attachment showing two mitoses in epidermal tissue forming cyst, numerous leucocytes in fish tissue near point of attachment of glochidium and large blood vessel enclosed within the mantle cavity.

Fig. 7. Cross-section of glochidium thirty minutes after attachment showing mitoses in tissue forming cyst, also in fish tissue enclosed between the valves of the glochidium. 

Fig. 8, Cross-section of glochidium one hour after attachment taken near anterior end of glochidium showing the cyst almost completely formed.

Fig. 9. Cross-section of glochidium of symphynota complanata two hours after attachment to the gill of fish, showing complete implanation of glochidium, numerous capillaries and large intercellular spaces in tissue of cyst.

Fig. 10. Sagittal section of glochidium forty-eight hours after attachment showing more compact appearance of tissue at this stage and three mitoses below glochidium.

Fig. 11. Cross-section of glochidium elghty-four days after attachment showing intercellular spaces in tissue of cyst.

Fig. 12. Frontal section of glochidium one hundred and one days after attachment showing large inter-cellular spaces and cells connected by long protoplasmic processes.

Fig. 13. Cross-section of glochidium one hundred and fourteen days after attachment showing the young mussel leaving the fish and the tissue of cyst degenerating. 

Fig. 14. Cross-section of glochidium of symphynota complanata attached to fin of fish, forty-eight hours after attachment showing the fish tissue enclosed between the valves of the glochidium.

Fig. 15. Glochidium fifteen minutes after attachment.

Fig. 16. Glochidium thirty minutes after attachment.

Fig. 17. Glochidium one hour after attachment.

Fig. 18. Glochidium forty-eight hours after attachment. 



\section{LITERATURE.}

1. Braun, $M_{\bullet}$, Über die postembryonale Entwicklung unserer süszwassermuscheln. Zool. Anz. Bd. I, 1878.

2. Faussek, V. Über den Parasitismus der Anodonta-Larven in der Fischhaut. Biologisches Centralblatt. 1895.

3. Faussek, V. Uber den Parasitismus der Anodonta-Larven. Verhandlungen des $\mathrm{V}$. Internationalen Zoologen Congresses Berlin. 1901.

4. Harms, W. Zur Biologie und Entwicklungsgeschichte der Fluszperlmuschel. (Margaritana margaritifera Dupray). Zool. Anz. Ax. XXXI, 1907.

5. Harms, W. Über die postembryonale Entwicklung von Anodonta piscinalis. Zool. Anz. Bd. XXXI, 1907.

6. Harms, W. Die postembryonale Entwicklung von Unio pictorum und Unio tumidus. Zool. Anz. Bd. XXXII, 1908.

7. Lillie,F.R.The embryology of the Unionidae. Journ. of Morph. Vol. X, 1895.

8. Schierholz,C. Über Entwicklung der Unioniden. Denkschr. d. Math. Natur. Cl. d. Kais. Akad. d. Wiss. Bd. LV, Wien, 1888 . 

9. Schmidt, F. Beitrag zur Kenntniss der postembryonalen Entwicklung der Najaden. Arch. Naturgesch. Jahrg. 51, 1885. 



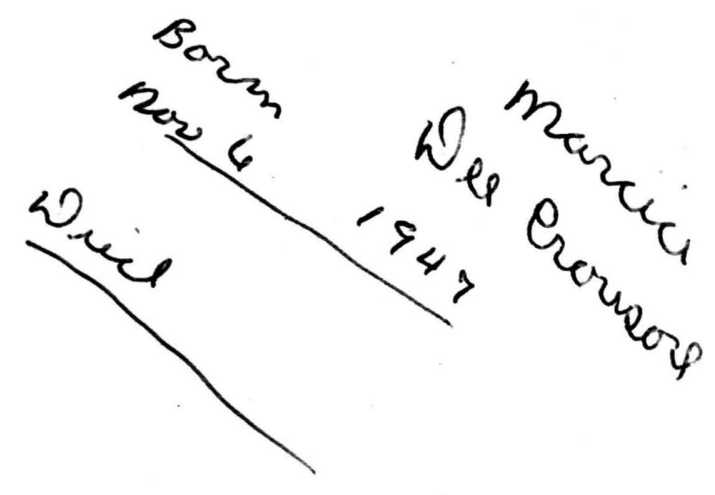




DUE HBPARETHENT

MAR $7 \quad 1986$

JUN 271986 MUN 12

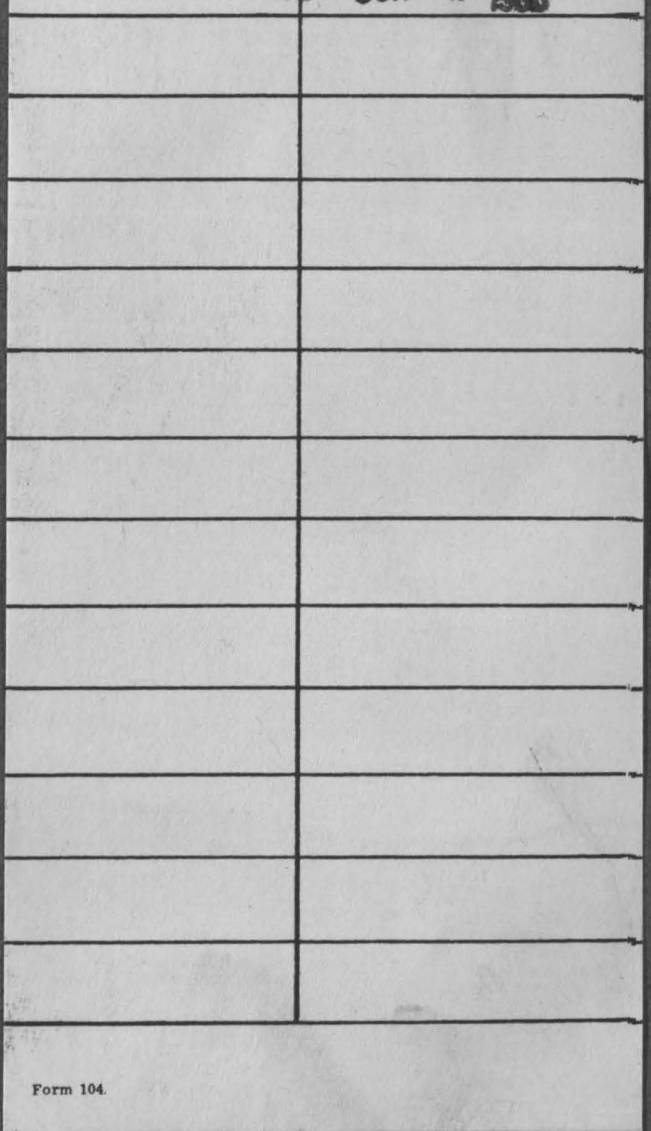




\section{$378.7 \mathrm{Mu}$ XY85}

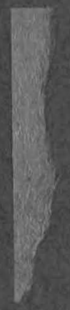

$$
\begin{aligned}
& \text { RECEIVEO } \\
& \text { NOV } 291909 \\
& \text { UWV OF MO. }
\end{aligned}
$$

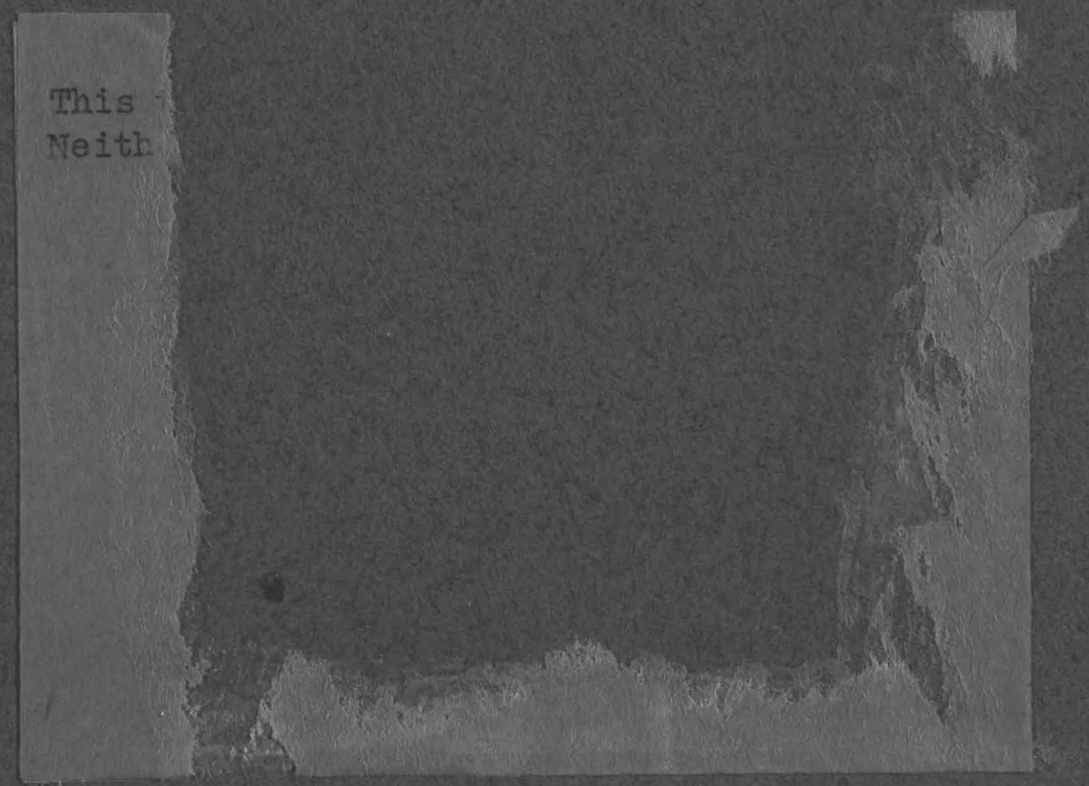




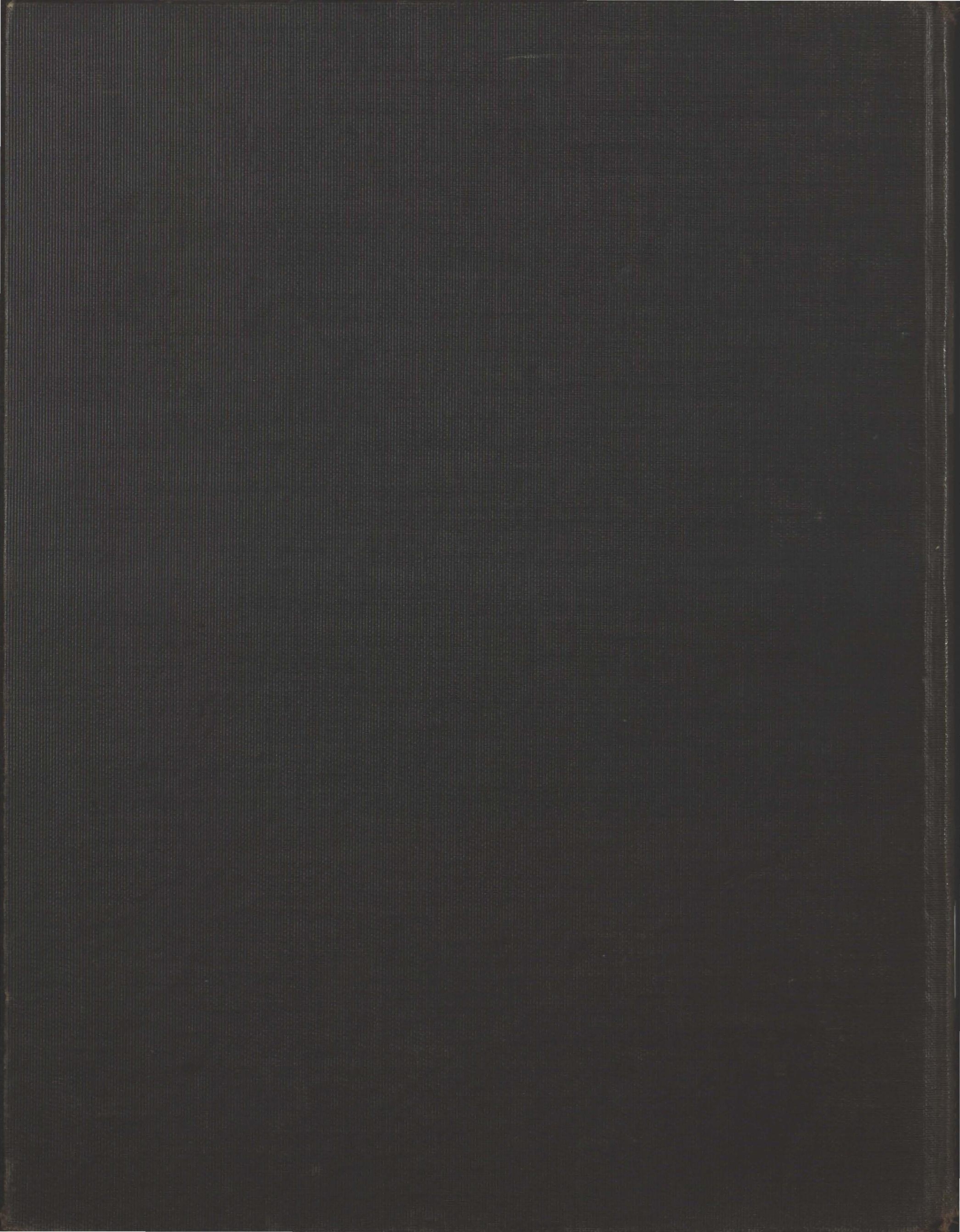

